\title{
Approximation of Empirical and ANN Based Solar Radiation Models for Four Smart Cities in Tamil Nadu with Most Prompting Input Parameters
}

\author{
V.Annapeachi, G.S.Gayathri, P.S.Manoharan
}

\begin{abstract}
The abundant source of Solar Radiation is possible in different latitude of Tamil Nadu. The several Empirical models have developed and accuracy of the model is further validated with Artificial Neural Network models. The ANN and Empirical model is developed with different combination of input attributes. The Approximate Sunshine Solar Radiation, Temperature and Relative Humidity are the input attributes. In this paper, it has been evaluated that combination of Approximate Sunshine Solar radiation and Temperature ANN based model is best for prediction of Daily Global Solar Radiation when compared to ST based Empirical model. The Correlation analysis is performedfor selection of most relevant input attributes. And hence the estimation of daily global solar radiation is performed with minimum number of input attributes. The training and testing of each model is performed by ANN Simulink model. And from this trainingofinputvariables, theoverfittingofthemodelisreduced. The estimated GSR is validated with experimental data which is collected from Tamil Nadu AgricultureUniversity.

Keywords - Approximate Sunshine Solar radiation, Artificial Neural Network, Empirical Models, Meteorological Parameters, Classification, South India.
\end{abstract}

\section{INTRODUCTION}

Solarenergyisthemostreliablesourceofenergythathas capacitytoendureandconversethelifeofalllivingorganism on earth. It is the renewable energy sources that has high potentialtomeetachallengearoundtheworldwithrespectto the environment issues associated with other non-renewable energy resources. The availability of solar radiation data is important solar energy application especially in the developing countries. Since the cost of radiation measuring instrument is high. And it is not practically possible to implement the pyranometer at all the location. Therefore itis essential to assessment solar radiation models based on commonlyavailablemeteorologicaldatasuchastemperature, sunshine radiation and relative humidity and so on.Selection of input parameter is the first step to develop models for estimation of daily global solar radiation. The prediction model has developed based on sunshine duration and clearnessindex[1].Predictingthedailyglobalsolarradiation bydayoftheyearinsixcitiesusingcurvefittinganalysisand regressioncoefficienthasbeenevaluatedfordifferentmodels [2]. Prediction of direct normal radiation and global solar radiation using neural network is proposed in [3].The

Revised Manuscript Received on November 15, 2019

Ms.V.ANNAPEACHI: Assistant professor at M.Kumarasamy College Of Engineering Karur, Tamil Nadu.

G.S.Gayathri assistant professor at M.Kumarasamy college of Engineering, karur, Tamilnadu.

P.S.Manoharan Associate Professorin Thiagarajar College of network configuration to select the number of hidden neuron andtransferfunctionofdifferentmodelshasbseenevaluated.

And similarly the estimation model is developed based on temperature, sunshine duration, clearness index and relative humidity.Inthis, theauthorextendedanideaforselectingthe most relevant input parameter for estimating the monthly averageddailyglobalsolarradiationfordifferentlatitude[4].

The empirical model such as angstrom linear and nonlinear models has developed for horizontal surface. And accuracy model is assessed for central region of India at Bhopal [5]. Regression analysis is performed for thirteen locations in Turkey using linear, quadratic and third order polynomial equation [6]. The author recommended the idea to select the geostatistical interpolation and stochastic interpolation simulation approach based on distance between the target area and nearest neighbour station [7]. The estimation of futuresolarirradianceusingtimeseriesanalysisisdiscussed. In this work the short term, medium and long term solar radiation forecasting has been carried out using an algorithm such that EWMA and WCMA. And then suggested that for short term forecasting WCMA algorithm is suitable and for long term forecasting pro energy algorithm is most suitable [8].Thenumberofinputvariableisreducedbyselectingmost relevant variables using support vector machine algorithm. And exploratory variables such as sunshine duration, temperature, relative humidity, longitude, latitude and altitude are identified as most relevant input variable $[9,10$, 11]. Artificial neural network modeling based Estimation of daily global solar radiation using on meteorological data has developed. The accuracy of the model is evaluated with and without considering particulate matter as an input variable [12]. The input predictor clearness index and sunshine durationismostimportantinputvariabletoestimatediffused solar radiation for humid - sub tropical climatic region [13, $14,15]$. Estimation of monthly global solar radiation by temperature and sunshine duration as an input parameter based model has analyzed for southern region of India [16, 17, 18]. The model has developed for prediction of global solar radiation based on selecting relevant input parameters using WEKA for Artificial Neural Network [19]. The accuracy and model has developed with ANN is detailed studied in following literatures [20-24]. Theunique

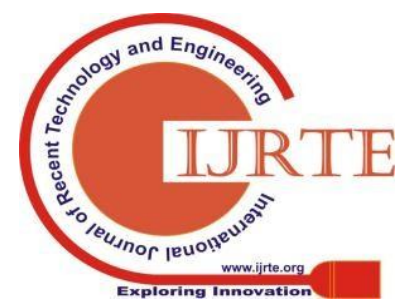




\section{Approximation of Empirical and ANN Based Solar Radiation Models for Four Smart Cities in Tamil Nadu with Most Prompting Input Parameters}

empirical model cannot be selected for southern region of Tamil Nadu, since as the latitude and longitude varies the prediction accuracy of the model is varied. Therefore, the correlation between different input parameters and output parameter has to be studied to evaluate the prediction accuracy. The computation time for empirical model ishuge. Hence, in this work it has concentrated to develop the more accurate and unique model with suitable input attributes to estimate daily global solar radiation is a significant research gap.

This work is focused on the identification of most relevant input attributes and to reduce complexity of the data using Artificial Neural Network. It also concentrated to improve the correlation coefficient and to reduce the error of selected solar radiation models. In this a comparison studies hasbeenperformedtoselectbestmodelamongtheANNand Empirical Model. Six ANN models are observed. Sunshine data is not available for all position. Therefore, the temperature based ANN models developed instead of sunshine data. ANN Hybrid model are developed with more thanoneattributecombination.Basedonthestatisticalerrors such as Mean Absolute Percentage Error, Root Mean Square Error, Mean Square Error, Mean Absolute Error and Correlation Coefficient, the accurate and unique model is selected for southern region. The developed ANN and Empirical models are evaluated for prediction of dailyglobal solarradiationforfourcitiesinTamilNadunamelyChennai, Coimbatore, Trichy and Madurai. The estimated daily global solar radiation standards of all models are compared with experimental data of Tamil Nadu Agriculture University (TNAU),Madurai.

\section{DATABASE}

The majority of literature not focused on Estimation of dailyglobalsolarradiationinsouthernregionofTamilNadu, were great potential exit. And most of literature models are developedwithsunshinedatawhichdataisnotpossibleforall location and accuracy of the model varies with different latitude. Fig. 1 shows the selected geographical study region in different latitude of Tamil Nadu in India. The meteorologicaldataiscollectedfromTamilNaduAgriculture University.

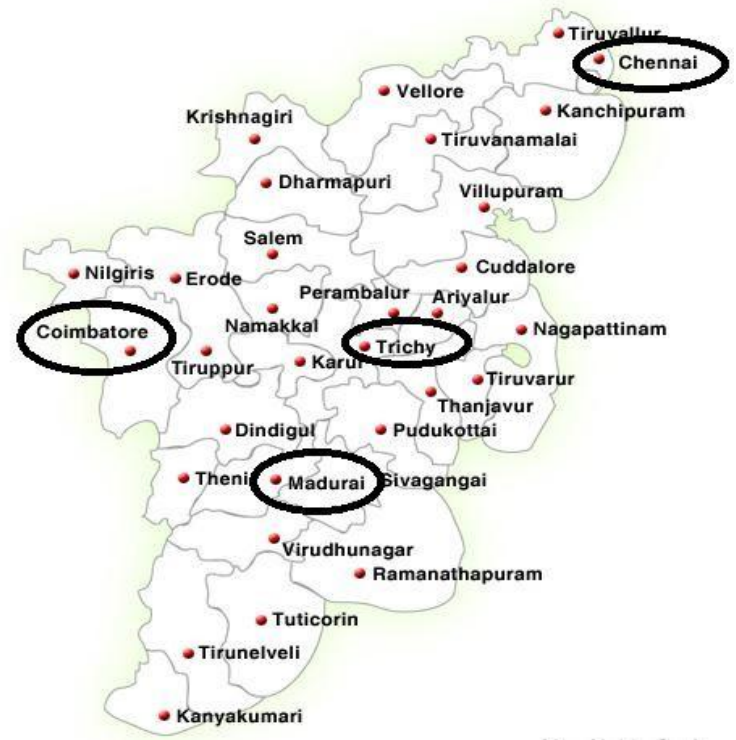

Fig. 1. Location of study region
The Approximate Sunshine Radiation, maximum temperature, minimum temperature and relative humidityare the input attribute selected for four different locations in Tamil Nadu were collected from TNAU. Latitude, longitude and climatic classification are the geographical parameters shown in Table I. And collected data is separated as a $2 / 3^{\text {rd }}$ trainingdatasetand $1 / 3^{\text {rd }}$ testingdataset.Thesedataisfurther processed with six ANN and thirteen Empirical models. MATLAB 2017a computing software is used for developing ANNmodelsandCurveFittingtoolsinMATLABisusedfor developing Empiricalmodels.

Table- I: Geographical parameters for particular location.

\begin{tabular}{|l|l|l|l|}
\hline Location & Latitude & Longitude & Climatic Zone \\
\hline Madurai & 9.92 & 78.12 & Southern \\
\hline Trichy & 10.79 & 78.70 & Cauvery delta \\
\hline Coimbatore & 11.01 & 76.95 & Western \\
\hline Chennai & 13.08 & 80.27 & North eastern \\
\hline
\end{tabular}

Here the four different zone performances are analyzed throughtrainingasetofdataandtestingremainingsetofdata. And comparative studies have made between the ANN and Empiricalmodels.

\section{EMPIRICAL MODEL DEVELOPMENT}

The five years solar radiation data is taken as input variable. In the present study, the models were developed by correlating the data of $\left(\frac{\bar{s}}{\bar{s}_{0}}\right)$. The approximate sunshine duration on the horizontal surface is considered about 120 $M J /\left(m^{2}\right.$ day $)$ ofmeasuredsolarradiationandthemaximum possible radiation $\left(\bar{s}_{0}\right)$ based on measured data from the considered location

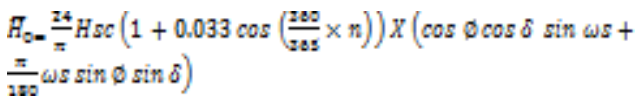

Where, $H_{s c}$ is the solar constant with the value of 1367 $\left(\begin{array}{l}\bar{H} \\ H_{0}\end{array}\right)$, istheratioofglobalsolarradiationattheearth surface $(\bar{H})$ and the extraterrestrial radiation $\left(H_{0}\right), \mathrm{n}$ is the Julian day of the year, $\emptyset$ is the location latitude, and $\delta$ and $\omega_{S}$ is mathematically defined as:

$\delta=23.45^{\circ} \sin \left[\frac{360[2 \mathrm{~g} 4+\mathrm{n})}{365}\right]$

$s_{0}=\frac{2}{15} \omega s$

$\cos \omega s=-\tan \emptyset \tan \delta$

The estimation of global solar radiation is depends on the meteorological data and geometrical data. Therefore, models can be classified in to three following:

1. Approximate Solar Radiation

2. Temperature

3. Hybrid parameters 


\section{Approximation of Empirical and ANN Based Solar Radiation Models for Four Smart Cities in Tamil Nadu with Most Prompting Input Parameters.}

\section{A.SUNSHINE - BASED MODELS STUDY SELECTED}

Thirteennumbersofmodelsareemployedforestimation of daily global solar radiation from commonly available meteorological parameters is available in the literature. Five models are developed with sunshine duration as input parameters. These models are developed and statistical index areanalyzedbyCurvefittingtoolinMATLABasreferredin literature [15]. Most of the literature has shown the highest accuracy result on sunshine based model. Hence, the clearness index is related with sunshineduration.

\section{Group 1}

The Angstrom and Prescott first order polynomial model is given by

$\frac{\bar{H}}{H_{0}}=a+b\left(\frac{\bar{s}}{s o}\right)$

The following Eq. (6-9) are obtained daily global solar radiation model based on DB for Madurai, Trichy, Coimbatore and Chennai.

$\frac{\bar{H}}{H_{0}}=0.891+0.090\left(\frac{\bar{s}}{s o}\right)$

$\frac{\bar{H}}{H_{0}}=-0.532+0.173\left(\frac{\bar{s}}{s o}\right)(7)$

$\frac{\bar{H}}{H_{0}}=-0.533+0.168\left(\frac{\bar{s}}{s o}\right)$

$\frac{\bar{H}}{H_{0}}=-0.536+0.177\left(\frac{\bar{s}}{s o}\right)$

\section{Group 2}

Kadir Bakirci [2017] developed the nonlinear Model such as thequadratic(second order polynomial)form.

$\frac{\bar{H}}{H_{0}}=a+b\left(\frac{\bar{s}}{s o}\right)+c\left(\frac{\bar{s}}{s o}\right)^{2}$

Where $a, b$ and $c$ are quadratic model regression coefficient. Eq.(11-14)asfollowbelowisthemodelsdevelopedforfour cities Vishnu and Annam [2018] proposed model for Madurai

$\frac{\bar{H}}{H_{0}}=0.310-0.542\left(\frac{\bar{s}}{s o}\right)+0.149\left(\frac{\bar{s}}{s o}\right)^{2}(11)$

Obtained model for Trichy location

$\frac{\bar{H}}{H_{0}}=-0.381+0.118\left(\frac{\bar{s}}{s o}\right)+0.495\left(\frac{\bar{s}}{s o}\right)^{2}$

Derived model for Western Zone (Coimbatore)

$\frac{\bar{H}}{H_{0}}=0.250-0.883\left(\frac{\bar{s}}{s o}\right)+0.902\left(\frac{\bar{s}}{s o}\right)^{2}$

Estimated second order polynomial model forChennai

$\frac{\bar{H}}{H_{0}}=-0.918+0.313\left(\frac{\bar{s}}{s 0}\right)-1.182\left(\frac{\bar{s}}{s 0}\right)^{2}$

\section{Group 3}

The third-order polynomial Liu and Jordan based Model are as follows;

$\frac{\bar{H}}{H_{n}}=a+b\left(\frac{\bar{Q}}{s o}\right)+c\left(\frac{\bar{Q}}{S_{0}}\right)^{2}+d\left(\frac{\bar{Q}}{S_{0}}\right)^{a}(15)$

$\frac{\bar{H}}{H_{0}}=-0.817+0.473\left(\frac{\bar{s}}{s 0}\right)-0.872\left(\frac{\bar{s}}{s 0}\right)^{2}+0.542\left(\frac{\bar{s}}{s 0}\right)_{(16)}$

$$
\begin{aligned}
& \frac{\bar{H}}{H_{\sigma}}=0.710-0.392\left(\frac{\bar{s}}{s \sigma}\right)+0.743\left(\frac{\bar{s}}{s \sigma}\right)^{2}-0.441\left(\frac{\bar{s}}{s o}\right)^{2} \\
& \frac{\bar{H}}{H_{\sigma}}=0.524-0.272\left(\frac{\bar{s}}{s \sigma}\right)+0.469\left(\frac{\bar{s}}{s \sigma}\right)^{2}-0.253\left(\frac{\bar{s}}{s \sigma}\right)^{2} \\
& \frac{\bar{H}}{H_{\sigma}}=0.682-0.381\left(\frac{\bar{s}}{s \sigma}\right)+0.712\left(\frac{\bar{s}}{s \sigma}\right)^{2}-0.252\left(\frac{\bar{s}}{s o}\right)^{2}
\end{aligned}
$$

\section{Group 4}

If the coefficient associated with exponential is negative then, its result in decreased value. If the coefficient associated with exponential is positive then, its result in increased value.

$\frac{\bar{H}}{H_{0}}=a\left(\frac{\bar{s}}{s o}\right)^{b}$

The following Eq. (21-24) are obtained daily global solar radiation model based on DB for Madurai, Trichy, Coimbatore and Chennai. It is the exponential modelderived for four cities by considering sunshine duration as the input parameters.

$\frac{\bar{H}}{H_{0}}=0.233\left(\frac{\bar{s}}{s o}\right)^{1.47}$

$\frac{\bar{H}}{H_{0}}=0.435\left(\frac{\bar{s}}{s o}\right)^{0.403}$

$\frac{\bar{H}}{H_{0}}=0.446\left(\frac{\bar{s}}{s o}\right)^{0.397}$

$\frac{\bar{H}}{H_{0}}=0.594\left(\frac{\bar{s}}{s o}\right)^{0.358}$

\section{Group 5}

The following Eq. (26-29) are obtained daily global solar radiation model based on DB for Madurai, Trichy, Coimbatore and Chennai. It is the natural logarithmic model derivedforfourcitiesbyconsideringsunshinedurationasthe inputparameters.

$$
\begin{aligned}
& \frac{\bar{H}}{H_{0}}=a+b \log \left(\frac{\bar{s}}{s o}\right) \\
& \frac{\bar{H}}{H_{0}}=-0.361+0.486 \log \left(\frac{\bar{s}}{s o}\right)
\end{aligned}
$$

$\frac{\bar{H}}{H_{0}}=-0.121+0.964 \log \left(\frac{\bar{s}}{s o}\right)$

$\frac{\bar{H}}{H_{0}}=-0.125+0.954 \log \left(\frac{\bar{s}}{s o}\right)$

$\frac{\bar{H}}{H_{0}}=0.126+0.100 \log \left(\frac{\bar{s}}{s o}\right)$

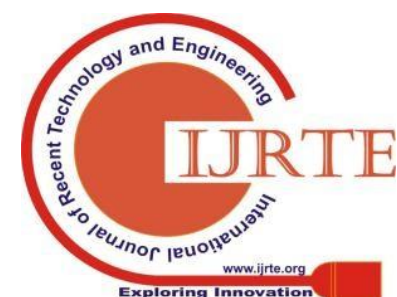




\section{B.TEMPERATURE BASED MODELS}

The four temperature based empirical models are developed.InsteadofSunshinedata, thetemperaturedataare used. Since Sunshine data is not readily available in every location.Thesefollowingmodelsaredevelopedasreferredin literature[11].

\section{Group 1}

The following Eq. (30-49) are obtained daily global solar radiation model based on DB for Madurai, Trichy, Coimbatore and Chennai. These are the model derived for four cities by considering Temperature as the input parameters.

$\frac{\bar{H}}{H_{0}}=\left(1-\exp (-a \Delta T)^{b}\right)$

$\frac{\bar{H}}{H_{0}}=\left(1-\exp (-0.511 \Delta T)^{0.905}\right)(31)$

$\frac{\bar{H}}{H_{0}}=\left(1-\exp (-0.751 \Delta T)^{0.769}\right)(32)$

$\frac{\bar{H}}{H_{0}}=\left(1-\exp (-0.179 \Delta T)^{0.201}\right)$

$\frac{\bar{H}}{H_{0}}=\left(1-\exp (-0.751 \Delta T)^{0.719}\right)$

\section{Group 2}

$\frac{\bar{H}}{H_{0}}=a\left(T_{\max -} T_{\min }\right)^{0.5}+b$

$\frac{\bar{H}}{H_{0}}=0.246\left(T_{\max -} T_{\min }\right)^{0.5}+0.420$

$\frac{\bar{H}}{H_{0}}=0.131\left(T_{\max }-T_{\min }\right)^{0.5}+0.327$

$\frac{\bar{H}}{H_{0}}=0.272\left(T_{\max -} T_{\min }\right)^{0.5}-0.516$

$\frac{\bar{H}}{H_{0}}=0.131\left(T_{\max }-T_{\min }\right)^{0.5}+0.327$

\section{Group 3}

$\frac{\bar{H}}{H_{0}}=a+b\left(\frac{T_{\min }}{T_{\max }}\right)$

$\frac{\bar{H}}{H_{0}}=0.294+0.434\left(\frac{T_{\min }}{T_{\max }}\right)$

$\frac{\bar{H}}{H_{0}}=0.251+0.117\left(\frac{T_{\min }}{T_{\max }}\right)$

$\frac{\bar{H}}{H_{0}}=0.501-0.817\left(\frac{T_{\min }}{T_{\max }}\right)$

$$
\frac{\bar{H}}{H_{0}}=0.253+-0.172\left(\frac{T_{\min }}{T_{\max }}\right)
$$

\section{Group 4}

$\frac{\bar{H}}{H_{0}}=\left(a+b\left(\frac{T_{\min }}{T_{\max }}\right)\right)\left(\frac{T_{\min }}{T_{\max }}\right)^{c}$

$\frac{\bar{H}}{H_{0}}=\left(0.588+0.593\left(\frac{T_{\min }}{T_{\max }}\right)\right)\left(\frac{T_{\min }}{T_{\max }}\right)^{0.389}$

$\frac{\bar{H}}{H_{0}}=\left(0.257+0.161\left(\frac{T_{\min }}{T_{\max }}\right)\right)\left(\frac{T_{\min }}{T_{\max }}\right)^{0.688}$

$\frac{\bar{H}}{H_{0}}=\left(0.623+0.591\left(\frac{T_{\min }}{T_{\max }}\right)\right)\left(\frac{T_{\min }}{T_{\max }}\right)^{0.468}$

$$
\frac{\bar{H}}{H_{0}}=\left(0.254+0.116\left(\frac{T_{\min }}{T_{\max }}\right)\right)\left(\frac{T_{\min }}{T_{\max }}\right)^{0.688}
$$

\section{HYBRID BASED MODELS}

Here, four groups of models are developed with morethanoneattributesinputparameters. RelativeHumidity andApproximateSolarRadiationcombinationaredeveloped in first group. And the combination of Relative humidity and Temperature based models are performed in second group. Similarly three attribute combination has developed in third group. It involves attribute as Approximate Solar Radiation, Relative humidity and Temperature. And finally the fourth group has developed by the combination of Approximate Solar Radiation and Temperature.

\section{Group 1}

The following Eq. (50-54) are obtained daily global solar radiation model based on DB for Madurai, Trichy, Coimbatore and Chennai. These are the model derived for four cities by considering Approximate Solar Radiation and Relative humidity as the input parameters.

$\frac{\bar{H}}{H_{0}}=a+b\left(\frac{\bar{s}}{s o}\right)+c(R H)$

$\frac{\bar{H}}{H_{0}}=0.107+0.961\left(\frac{\bar{s}}{s o}\right)+0.114(R H)$

$\frac{\bar{H}}{H_{0}}=0.153+0.968\left(\frac{\bar{s}}{s o}\right)+0.343(R H)$

$\frac{\bar{H}}{H_{0}}=0.741+0.789\left(\frac{\bar{s}}{s o}\right)-0.118(R H)$

$$
\frac{\bar{H}}{H_{0}}=0.357+0.119\left(\frac{\bar{s}}{s o}\right)-0.866(R H)
$$




\section{Approximation of Empirical and ANN Based Solar Radiation Models for Four Smart Cities in Tamil Nadu with Most Prompting Input Parameters.}

\section{Group 2}

The following Eq. (55-59) are obtained daily global solar radiation model based on DB for Madurai, Trichy, Coimbatore and Chennai. These are the model derived for fourcitiesbyconsideringTemperatureandRelativehumidity as the inputparameters.

$$
\begin{aligned}
& \frac{\bar{H}}{H_{0}}=a+b\left(\frac{T_{\min }}{T_{\max }}\right)+c(R H)(55) \\
& \frac{\bar{H}}{H_{0}}=0.128+0.301\left(\frac{T_{\min }}{T_{\max }}\right)+0.951(R H)(56) \\
& \frac{\bar{H}}{H_{0}}=1.712-0.785\left(\frac{T_{\min }}{T_{\max }}\right)-0.116(R H)(57) \\
& \frac{\bar{H}}{H_{0}}=0.123+0.406\left(\frac{T_{\min }}{T_{\max }}\right)-0.754(R H) \\
& \frac{\bar{H}}{H_{0}}=1.082-0.274\left(\frac{T_{\min }}{T_{\max }}\right)-0.567(R H)
\end{aligned}
$$

\section{Group 3}

The following Eq. (60-64) are obtained daily global solar radiation model based on DB for Madurai, Trichy, Coimbatore and Chennai. These are the model derived for four cities by considering Approximate Solar Radiation, Temperature and Relative humidity as the input parameters.

$$
\begin{aligned}
& \frac{\bar{H}}{H_{0}}=a+b\left(\frac{\bar{s}}{s o}\right)+c\left(\frac{T_{\min }}{T_{\max }}\right)+d(R H) \\
& \frac{\bar{y}}{H_{4}}=0.762+0.964\left(\frac{5}{g}\right)+1.149\left(\frac{T_{m}}{t_{\max }}\right)+0.267(R H)
\end{aligned}
$$

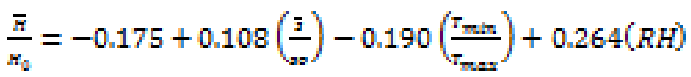

$$
\begin{aligned}
& \frac{\overline{\underline{X}}}{x_{0}}=0.880+0.578\left(\frac{\bar{z}}{z z}\right)-0.689\left(\frac{T_{\min }}{\tau_{\operatorname{man}}}\right)-4.63(R H] \\
& \frac{\overline{\underline{x}}}{x_{0}}=1.022+0.122\left(\frac{\bar{z}}{g z}\right)-0.741\left(\frac{r_{\operatorname{man}}}{r_{\max }}\right)+0.234(R H)
\end{aligned}
$$

\section{Group 4}

The following Eq. (60-64) are obtained daily global solar radiation model based on DB for Madurai, Trichy, Coimbatore and Chennai. These are the model derived for four cities by considering Approximate Solar Radiation and Temperature as the input parameters.

$$
\begin{aligned}
& \frac{\bar{H}}{H_{0}}=a+b\left(\frac{\bar{s}}{s o}\right)+c\left(\frac{T_{\min }}{T_{\max }}\right)(65) \\
& \frac{\bar{H}}{H_{0}}=0.209+0.104\left(\frac{\bar{s}}{s 0}\right)+1.611\left(\frac{T_{\min }}{T_{\max }}\right)(66) \\
& \frac{\bar{H}}{H_{0}}=-0.409+0.113\left(\frac{\bar{g}}{s_{0}}\right)+0.411\left(\frac{T_{\min }}{T_{\max }}\right)(67) \\
& \frac{\bar{H}}{H_{0}}=0.760+0.435\left(\frac{\bar{s}}{s_{0}}\right)-0.783\left(\frac{T_{\min }}{T_{\max }}\right)(68) \\
& \frac{\bar{H}}{H_{0}}=-0.487+0.119\left(\frac{\bar{g}}{s_{0}}\right)+0.477\left(\frac{T_{\min }}{T_{\max }}\right)
\end{aligned}
$$

\section{ANN BASED MODEL DEVELOPMENT}

ANN is simple to predict to predict the behavior of complex systems with multiple input domains. The ANN Gradient descent approach is used to functioned ANNoutput and the target. The ANN target can be attained by adjusting weightsandbiasesofANNoutput.ANNcanperformatasks thatwhichcannotperformbylinearmethod.ANNlearnsand does not need to be reprogrammed. Simultaneously, the performance of multiple inputs can be analyzed. The four ANN models to assess the daily global solar radiation are given in Table II. The model has developed by using single input parameter such as Approximate Solar Radiation, Relative Humidity andTemperature.

Table -II: Models developed by using ANN

\begin{tabular}{|c|c|}
\hline Models & Variables \\
\hline ANN-S & S, So \\
\hline ANN-T & $T_{\max }, T_{\min }$ \\
\hline $\begin{array}{c}\text { ANN-ST, TH, } \\
\text { SH,STH }\end{array}$ & $\mathrm{S}, \mathrm{S}, T_{\max }, T_{\min }, \mathrm{RH}$ \\
\hline
\end{tabular}

Andalsomodelshavedevelopedbyusingthecombinationof Approximate Solar Radiation, temperature and relative humidityascombinationofinputvariables. Thecorrelation result for different attribute is presented in a Table III. Maximum temperature is the first input parameter gives the best correlation of 0.780 to assess the solar radiation. Approximate Solar Radiation is the second input parameter gives the correlation of 0.666 . Relative humidity gives the leastcorrelationof0.336.Predictionresultisbetter,whenthe $\mathrm{R}$ value ishigher.

Table -III: Correlation developed by ANN for different attributes with measured GSR

\begin{tabular}{|l|c|c|}
\hline Input Variable & Correlation R & Rank \\
\hline Bright sunshine & 0.666 & 2 \\
\hline $\mathrm{T}_{\max }$ & 0.780 & 1 \\
\hline $\mathrm{T}_{\text {min }}$ & 0.531 & 3 \\
\hline Relative Humidity & 0.3361 & 4 \\
\hline
\end{tabular}

The correlation Coefficient $\mathrm{R}$ values ranges between 0.336 and 0.666. The necessity of the Correlation analysis is to reduce the number of input attributes. And also it is used to obtainaresultthathowtheoutputdataisrelevanttotheinput attributes.

Regressionplots

developed between input attributes and output data using neural network is shown inFig. 
2. Maximumtemperatureisthefirstinputparametergivesthe best correlation of 0.780 to enhance the prediction of global solar radiation.

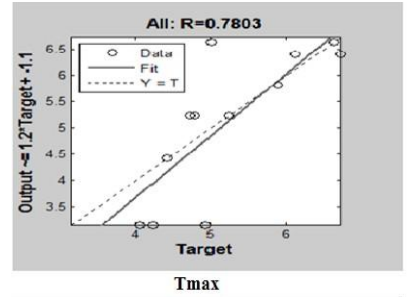

All: $R=-0.53151$

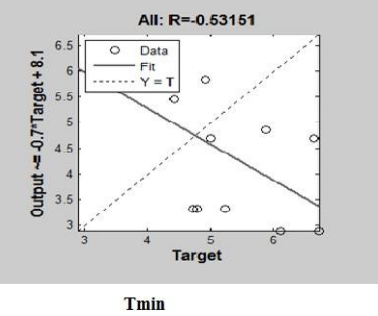

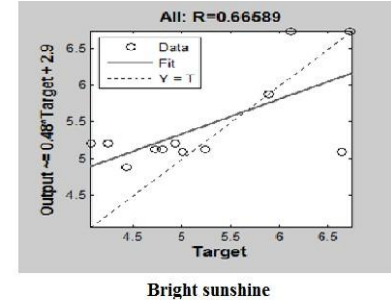

Bright sunshine

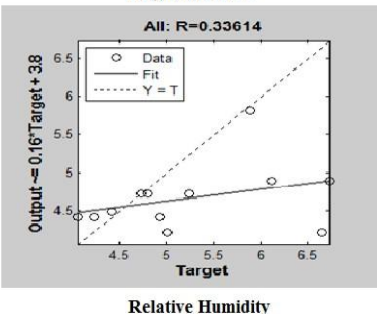

Relative Humidity
Fig .2. Regression plots developed between input attributes and output data using neural network

\section{A. TESTING PERFORMANCE}

The selected best ANN-ST model is tested for four sites in Tamil Nadu. The best model is selected based on the trainingerror.Themodelhasalesserrorandhighcorrelation isselectedasthebestmodel.Fig.3givestheSimulinkmodel for testing analysis. Initially the network has the threelayers. Input as a first layer, hidden is the middle layer and target as an output layer. In input layer, two parameters are taken as input such as Sunshine radiation and temperature- minimum and maximum. The log sigmoidal and purlin are thefunction of the network. Since, the solar irradiance data varied for every month. It is also a seasonal data which is lead to nonlinear data.

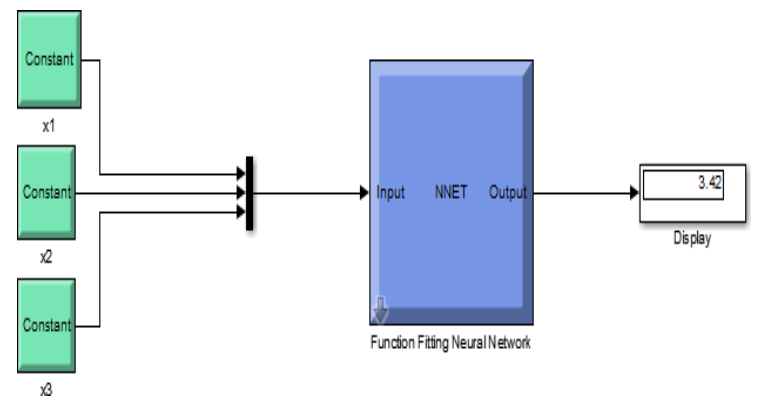

Fig. 3. Simulink of selected best ST-ANN model

In hidden layer five neurons are used and weights are obtained. Hidden to output layer is the second layer where a singleoutputisobtained.Thesolarirradiancedataisobtained intheoutputlayer.TheSimulinkmodelistestedforfoursites and daily solar irradiance is predicted. The weights adjustmentinthenetworkisshowninFig.4.Thefiveneurons carries the weights in the hidden layer is product with the input parameters. The single output solar irradiance is predicted very accurately based on the collecteddata.

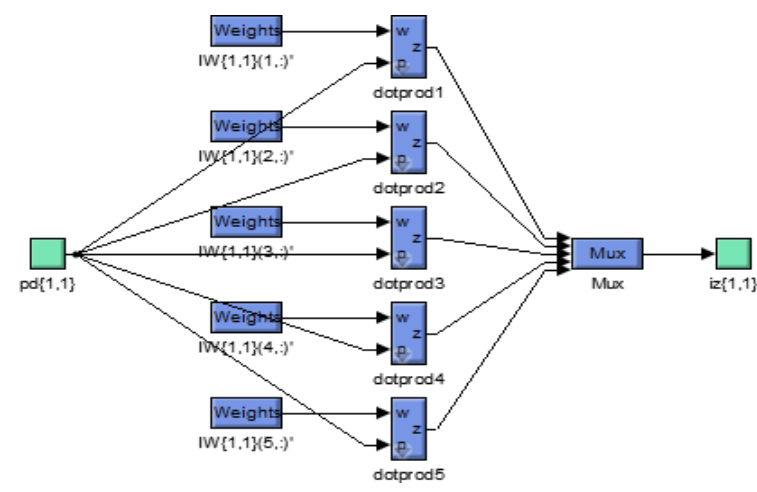

Fig. 4. Weights adjustment of the model network

Andregressioncurveisdrawnbetweenthemeasuredand the observed data. The converged weights are given in equations 70 to 73 . The weights and biases between the inputandthehiddenneuronsaregivenin72and73. The weights in the hidden neurons are dot product with the inputparameters.

$\left[\begin{array}{lll}W 11 & W 12 & W 13 \\ W 21 & W 22 & W 23 \\ W 31 & W 32 & W 33 \\ W 41 & W 42 & W 43 \\ W 51 & W 52 & W 53\end{array}\right]=\left[\begin{array}{ccc}-0.058 & 1.967 & 2.426 \\ -1.672 & -1.475 & 0.916 \\ -1.005 & -0.026 & 2.060 \\ -1.316 & 1.370 & 1.144 \\ 0.103 & -1.441 & 1.683\end{array}\right]$
$\left[\begin{array}{l}b 1 \\ b 2 \\ b 3 \\ b 4 \\ b 5\end{array}\right]=\left[\begin{array}{c}2.532 \\ 0.876 \\ -0.418 \\ -1.961 \\ -2.689\end{array}\right]$

Where, W11 - Weight between first input parameter and first hidden neuron.

W12 - Weight between first input parameter and second hiddenneuron.

W22 - Weight between second input parameter and second hiddenneuron.

W33 - weight between third input parameter and third hidden neuron.

$b 1$ is the bias of the first neuron.

$b 2$ is the bias of the second neuron.

The weight and bias between the hidden neuron and output layer is given in the equations 72 to 73 . It is second layer of the network. 


\section{Approximation of Empirical and ANN Based Solar Radiation Models for Four Smart Cities in Tamil Nadu with Most Prompting Input Parameters.}

$\left[\begin{array}{l}W 31 \\ W 32 \\ W 33 \\ W 34 \\ W 35\end{array}\right]=\left[\begin{array}{c}-0.755 \\ -0.309 \\ 1.296 \\ 0.384 \\ -0.518\end{array}\right]$

\section{$[b]=[0.408]$}

Where, Wijistheweightbetweensecondhiddenlayeroutput and the outputlayer.

$b$ is the bias of the hidden neuron.

The correlation between measured and observed GSR is showninFig.5.Fromthisfigureitisanalysedthatagreement between the estimated and measured daily global solar radiation is veryhigh.

The regression coefficient $\mathrm{R}^{2}$ value for Madurai is 0.9908 and 0.9828 for Trichy, which shows the higher accuracy for selected smart cities. Similarly the regression coefficient for Coimbatore and Chennai is 0.93813 and 0.99614.The ANN model performance gives the higher accuracy than empirical model. By the comparative studiesit is analysed that for south India the ST model is best for assessment of daily global solarradiation.

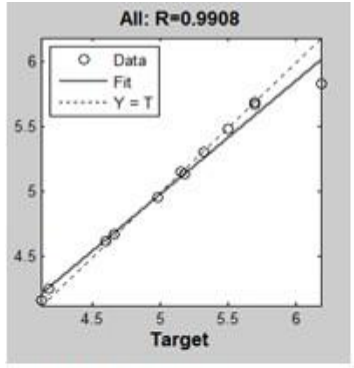

MADURAI

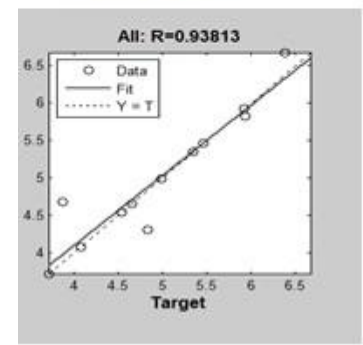

COIMBATORE

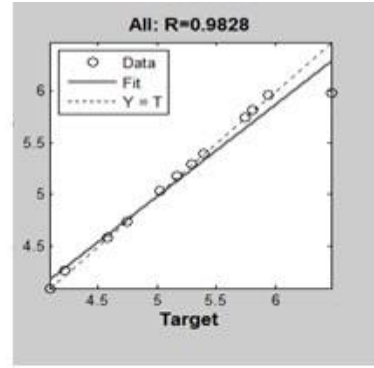

TRICHY

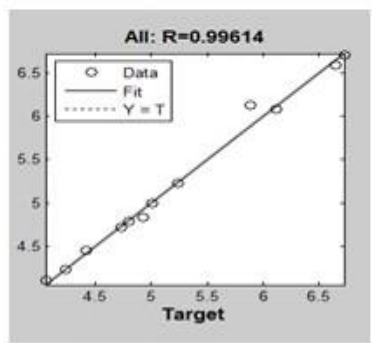

CHENNAI
Fig. 5. Scatter plots showing the correlation between measured and observed GSR from selected model ANN (H4 or ST).

\section{OVERALL PERFORMANCE}

The performances of sunshine, temperature and hybrid empirical model are analyzed through the Curve Expert Software. Each location was analyzed with thirteen models. An error statistics and empirical coefficients result of the thirteen empirical models for Madurai and Trichy are presented in Table IV. For Madurai Hybrid model H4 gives the best GSR estimation with least $\mathrm{MSE}=0.20\left(\mathrm{MJm}^{-4} \mathrm{day}^{-1}\right)$, $\mathrm{MAPE}=5.1 \%, \mathrm{RMSE}=0.440\left(\mathrm{MJm}^{-2} \mathrm{day}^{-1}\right), \mathrm{MAE}=0.224(\mathrm{MJ}$ $\mathrm{m}^{-2} \mathrm{day}^{-1}$ ) and regression coefficient value of 0.962 .Sunshine based model S5 gives the better GSR estimation with $\mathrm{MSE}=0.34\left(\mathrm{MJm}^{-4} \mathrm{day}^{-1}\right)$,
MAPE $=3.6 \%$, RMSE $=0.580\left(\mathrm{MJ} \mathrm{m}^{-2} \mathrm{day}^{-1}\right), \mathrm{MAE}=0.153(\mathrm{MJ}$ $\mathrm{m}^{-2}$ day $\left.^{-1}\right)$ and this model can be used for the location where the sunshine radiation is only available.

Table -IV: Error statistics and Empirical coefficient of estimation of daily GSR in Madurai and Trichy

\begin{tabular}{|c|c|c|c|c|c|c|c|c|c|}
\hline \begin{tabular}{|l|} 
Model' \\
Location
\end{tabular} & MAE & MAPE & MSE & RISE & $\mathrm{R}$ & \multicolumn{4}{|c|}{ EMPIRICAL COE FFICIENTS } \\
\hline MADIRAI & $\left(\mathrm{MJ} \mathrm{m}^{-2} \mathrm{day}^{-1}\right)$ & $(\%)$ & $\left(\mathrm{MI}^{2} \mathrm{~m}^{-1} \mathrm{day}^{-1}\right)$ & $\left(\mathrm{MJ} \mathrm{m}^{-2} \mathrm{day}^{-1}\right)$ & & a & b & c & d \\
\hline S1 & 0.11 & 2.2 & 0.33 & 0.57 & 0.85 & -0.024 & 0.882 & & \\
\hline S2 & -0.18 & 3.1 & 0.29 & 0.53 & 0.90 & \begin{tabular}{|l|l|l|l|l}
0.181 \\
\end{tabular} & -0.570 & 0.581 & \\
\hline S3 & -0.07 & 1.2 & 0.29 & 0.54 & 0.86 & -0.817 & 0.473 & -0.872 & 0.542 \\
\hline S4 & 0.16 & 4.0 & 0.32 & 0.56 & 0.91 & & 0.908 & & \\
\hline S5 & 0.15 & 3.6 & 0.34 & 0.58 & 0.86 & -0.361 & 0.486 & & \\
\hline $\mathrm{T1}$ & 0.45 & 4.5 & 0.65 & 0.810 & 0.06 & 0.511 & 0.905 & & \\
\hline T2 & 0.46 & 9.2 & 0.65 & 0.804 & 0.180 & 0.246 & 0.420 & & \\
\hline T3 & 0.47 & 1.0 & 0.63 & 0.801 & 0.219 & 0.294 & 0.434 & & \\
\hline T4 & 0.12 & 2.0 & 0.65 & 0.804 & 0.359 & 0.588 & 0.593 & 0.389 & \\
\hline H1 & 1.21 & 2.5 & 0.189 & 0.434 & 0.925 & \begin{tabular}{|l|l|}
0.107 \\
\end{tabular} & 0.961 & 0.114 & \\
\hline H2 & -1.13 & 2.4 & 0.462 & 0.679 & 0.745 & 0.128 & 0.301 & 0.951 & \\
\hline $\mathrm{H} 3$ & -0.26 & 5.5 & 0.211 & 0.459 & 0.952 & $\begin{array}{l}0.762 \\
\end{array}$ & 0.964 & 1.149 & 0.267 \\
\hline $\mathrm{H} 4$ & 0.224 & 5.1 & 0.200 & 0.440 & 0.962 & \begin{tabular}{|l|}
0.209 \\
\end{tabular} & 0.104 & \begin{tabular}{ll|l}
1.611 \\
\end{tabular} & \\
\hline \begin{tabular}{|l|} 
Model \\
Location \\
\end{tabular} & $\frac{\mathrm{MAE}}{\mathrm{MAE}}$ & MAPE & MSE & RMSE & $\mathrm{R}$ & \multicolumn{4}{|c|}{ EMPIRICAL COE FFICIENTS } \\
\hline \begin{tabular}{|l|} 
TRICHY \\
\end{tabular} & $\left(\mathrm{MJ} \mathrm{m}^{2} \mathrm{day}^{-1}\right)$ & $(\%)$ & \begin{tabular}{|l|}
$\left(\mathrm{MJ}^{2} \mathrm{~m}^{\mathrm{T}} \mathrm{day} \mathrm{y}^{-1}\right)$ \\
\end{tabular} & $\mid\left(\mathrm{MJ} \mathrm{m}^{2} \mathrm{dar}^{-12}\right)$ & & a & b & c & d \\
\hline S1 & 0.63 & 1.3 & 1.13 & 1.06 & 0.752 & -0.532 & 0.173 & & \\
\hline S2 & 0.66 & 1.4 & 1.19 & 1.09 & 0.753 & -0.381 & 0.118 & 0.495 & \\
\hline S3 & 0.7 & 1.5 & 1.26 & 1.12 & 0.751 & 0.710 & -0.392 & 0.743 & -0.441 \\
\hline \$4 & 0.09 & 1.0 & 1.14 & 1.07 & 0.754 & 0.435 & 0.403 & & \\
\hline S5 & 0.53 & 1.1 & 1.13 & 1.06 & 0.756 & -0.121 & 0.964 & & \\
\hline $\mathrm{T1}$ & 0.21 & 4.4 & 0.702 & 0.837 & 0.364 & 0.751 & 0.769 & & \\
\hline T2 & 0.22 & 4.6 & 0.698 & 0.835 & 0.37 & 0.131 & 0.327 & & \\
\hline T3 & 0.23 & 4.8 & 0.701 & 0.837 & 0.368 & $\mathrm{ccc}$ & 0.117 & & \\
\hline T4 & 0.06 & 1.2 & 0.734 & 0.856 & 0.38 & 0.257 & 0.161 & 0.688 & \\
\hline H1 & 0.12 & 3.0 & 0.28 & 0.529 & 0.932 & 0.153 & 0.968 & 0.343 & \\
\hline H2 & -0.44 & 9.2 & 0.594 & 0.770 & 0.66 & 1.712 & -0.785 & -0.116 & \\
\hline H3 & 0.26 & 5.4 & 0.283 & 0.531 & 0.934 & -0.175 & 0.108 & -0.190 & 0.264 \\
\hline H4 & 0.16 & 3.2 & 0.29 & 0.538 & 0.95 & \begin{tabular}{|l|}
-0.409 \\
\end{tabular} & 0.113 & 0.411 & \\
\hline
\end{tabular}

And further the temperature based model gives the worst performance for this location. Hybrid model $\mathrm{H} 2$, gives the worst performance compared to other hybrid models. Since the model is based on Temperature and Relative Humidity.It does not depend on Sunshine radiation. And it can analyze that combination of sunshine radiation and Temperature (H4 or ST) based model is the most relevant input parameter to predict the DGSR. Trichy is very hottest city in the Tamil Naduandislocatedonthecentralsouth-easternofIndia.For

Trichy, the best performance is presented by model $\mathrm{H} 4$ in hybrid category with $\mathrm{R}$ value of $0.95, \mathrm{MSE}=0.29$ (MJ m $\left.{ }^{4} \mathrm{day}^{-1}\right), \quad$ MAPE $=3.2 \%, \quad \mathrm{RMSE}=0.538 \quad\left(\mathrm{MJ} \mathrm{m}^{-2} \mathrm{day}^{-1}\right)$, MAE $=0.162\left(\mathrm{MJ} \mathrm{m}^{-2} \mathrm{day}^{-1}\right)$. In sunshine model S5 gives the best performances with $\mathrm{R}$ value of $0.756, \mathrm{MSE}=1.13$ $\left(\mathrm{MJ} \mathrm{m}{ }^{-4} \mathrm{day}^{-1}\right), \mathrm{MAPE}=1.1 \%, \mathrm{RMSE}=1.06\left(\mathrm{MJ} \mathrm{m}^{-2} \mathrm{day}^{-1}\right)$, $\mathrm{MAE}=0.532\left(\mathrm{MJ} \mathrm{m}^{-2} \mathrm{day}^{-1}\right)$. Temperature based model gives the worst performance. Since according to the climatic condition, the minimum and maximum temperature of the southeasternregionvariesrandomlyforeachday.Hencethe temperature based models is not suited for south eastern region of India. Similarly, thirteen models are performed for Chennai and Coimbatore. Table V gives a summary of error statistics and empirical coefficients of the thirteen empirical models for south western and south central are presented in India. Chennai is located on the north eastern of India and it has tropical wet and dry climate. For Chennai, the best performance is presented by model $\mathrm{H} 4$ in hybrid category with regressioncoefficient $\mathrm{R}=0.987, \mathrm{MSE}=0.165$ (MJ m ${ }^{4}$ day $\left.^{-1}\right)$, MAPE $=1.1 \%$, $\mathrm{RMSE}=0.404 \quad\left(\mathrm{MJ} \mathrm{m}^{-2} \mathrm{day}^{-1}\right)$,

\section{Published By:}


MAE $=0.08\left(\mathrm{MJ} \mathrm{m}^{-2} \mathrm{day}^{-1}\right) . \mathrm{S} 4$ is the second best model with $\mathrm{R}=0.78, \quad \mathrm{MSE}=1.17 \quad\left(\mathrm{MJ} \quad \mathrm{m}^{-4} \mathrm{day}^{-1}\right), \quad \mathrm{MAPE}=1.1 \%$, RMSE $=1.08\left(\mathrm{MJ} \mathrm{m}^{-2} \mathrm{day}^{-1}\right), \mathrm{MAE}=0.78\left(\mathrm{MJ} \mathrm{m}^{-2} \mathrm{day}^{-1}\right)$. The thirdbestmodelisT3intemperaturecategorywith $\mathrm{R}=0.659$, MSE $=0.75\left(\mathrm{MJ} \mathrm{m}^{-4}\right.$ day $\left.^{-1}\right), \mathrm{MAPE}=1.8 \%$, RMSE $=0.867(\mathrm{MJ}$ $\mathrm{m}^{-2}$ day $\left.^{-1}\right)$, MAE $=0.09\left(\mathrm{MJm}^{-2}\right.$ day $\left.^{-1}\right)$.

Table-V:ErrorstatisticsandEmpiricalcoefficientof estimationofdailyGSRinChennaiandCoimbatore

\begin{tabular}{|c|c|c|c|c|c|c|c|c|c|}
\hline $\begin{array}{l}\text { Model/ } \\
\text { Location }\end{array}$ & MAAE & MAPE & MSE & RISE & $\mathrm{R}$ & \multicolumn{4}{|c|}{ EMPIRICAL COFFFICINTS } \\
\hline CHENNAI & $\left(\mathrm{MJ} \mathrm{m}^{-2} \mathrm{day}^{-1}\right)$ & (\%) & $\left(\mathrm{MI}^{2} \mathrm{~m}^{-\mathrm{d}} \mathrm{day} \mathrm{y}^{-1}\right)$ & $\left(\mathrm{MJ} \mathrm{m}^{-1} \mathrm{day}^{-1}\right)$ & & $\mathrm{a}$ & $\mathrm{b}$ & c & d \\
\hline s1 & -0.75 & 1.5 & 1.15 & 1.07 & 0.77 & -0.536 & 0.177 & & \\
\hline 52 & -0.67 & 1.3 & 1.21 & 1.10 & 0.76 & -0.918 & 0.313 & -1.182 & \\
\hline \$3 & -1.69 & 3.0 & -4.21 & 2.05 & 0.75 & 0.682 & -0.381 & 0.712 & -0.252 \\
\hline$\$ 4$ & -0.59 & 1.1 & 1.17 & 1.08 & 0.78 & 0.594 & 0.358 & & \\
\hline$\$ 5$ & -1.55 & 3.1 & 1.15 & 1.07 & 0.77 & 0.126 & 0.100 & & \\
\hline T1 & 0.13 & 2.6 & 0.657 & 0.81 & 0.06 & 0.751 & 0.719 & & \\
\hline T2 & 0.08 & 1.6 & 0.725 & 0.851 & 0.645 & 0.131 & 0.327 & & \\
\hline T3 & 0.09 & 1.8 & 0.73 & 0.854 & 0.637 & 0.253 & -0.172 & & \\
\hline T4 & 0.04 & 8.2 & 0.75 & 0.867 & 0.659 & 0.254 & 0.116 & 0.688 & \\
\hline H1 & 0.11 & 2.1 & 0.174 & 0.417 & 0.984 & 0.357 & 0.119 & -0.866 & \\
\hline H2 & 0.27 & 5.4 & 0.981 & 0.990 & 0.19 & 1.082 & -0.274 & -0.567 & \\
\hline H3 & -0.19 & 3.8 & 0.23 & 0.479 & 0.971 & 1.022 & 0.122 & -0.741 & 0.234 \\
\hline H4 & 0.08 & 1.1 & 0.165 & 0.404 & 0.987 & -0.487 & 0.119 & 0.447 & \\
\hline \begin{tabular}{|l|} 
Model \\
Location
\end{tabular} & TIAF & MAPE & $\overline{\text { MSE }}$ & RISE & $\bar{R}$ & \multicolumn{4}{|c|}{ EMPRICAL COEFFCIENTS } \\
\hline \begin{tabular}{|l|} 
Coimbatore \\
\end{tabular} & $\left(\mathrm{NJ}^{-2} \mathrm{day}^{-1}\right)$ & $(\%)$ & $\left(\mathrm{IIJ}^{2} \mathrm{~m}^{-1} \mathrm{day^{-1 }}\right)$ & $\left(\mathrm{NJ} \mathrm{m}^{-2} \mathrm{day}^{-1}\right)$ & & a & b & c & d \\
\hline \$1 & -128 & 2.3 & 139 & 1.17 & 0.60 & -0.533 & 0.168 & & \\
\hline$\$ 2$ & -155 & 2.8 & 1.42 & 1.19 & 0.63 & 0.250 & -0.883 & 0.902 & \\
\hline 83 & -1.89 & 3.4 & 1.42 & 1.19 & 0.68 & 0.524 & -0.272 & 0.469 & -0.253 \\
\hline S4 & \begin{tabular}{|l|}
-0.97 \\
\end{tabular} & 1.7 & 1.37 & 1.17 & 0.62 & 0.446 & 0.397 & & \\
\hline 85 & -123 & 2.2 & 1.41 & 1.18 & 0.59 & -0.125 & 0.954 & & \\
\hline T1 & 0.16 & 2.1 & 0.453 & 0.673 & 0.812 & 0.179 & 0.201 & & \\
\hline T2 & 0.07 & 1.2 & 0.454 & 0.6737 & 0.864 & 0.272 & -0.516 & & \\
\hline T3 & 0.1 & 1.8 & 0.458 & 0.676 & 0.861 & 0.501 & -0.817 & & \\
\hline T4 & 0.06 & 1.1 & 0.476 & 0.68 & 0.865 & 0.623 & 0.591 & 0.468 & \\
\hline H1 & 0.03 & 5.2 & 0.459 & 0.677 & 0.875 & 0.741 & 0.789 & -0.118 & \\
\hline H2 & -0.16 & 2.3 & 0.505 & 0.710 & 0.84 & 0.123 & 0.406 & -0.754 & \\
\hline H3 & -0.27 & 4.9 & 0.457 & 0.676 & 0.87 & 0.880 & 0.578 & -0.689 & -4.63 \\
\hline H4 & -0.04 & 2.1 & 0.40 & 0.632 & 0.918 & 0.760 & 0.435 & -0.783 & \\
\hline
\end{tabular}

CoimbatoreislocatedonthesouthwesterninIndiaandithas a pleasant climate. For Coimbatore, the best performance is presented by model $\mathrm{H} 4$ in hybrid category with regression coefficient $\mathrm{R}=0.918, \quad \mathrm{MSE}=0.40 \quad\left(\mathrm{MJ} \quad \mathrm{m}^{-4} \mathrm{day}^{-1}\right)$, MAPE $=2.1 \%$, RMSE $=0.632\left(\mathrm{MJ} \mathrm{m}^{-2} \mathrm{day}^{-1}\right), \mathrm{MAE}=-0.04(\mathrm{MJ}$ $\left.\mathrm{m}^{-2} \mathrm{day}^{-1}\right)$. T4 is the second best model with $\mathrm{R}=0.865$, $\mathrm{MSE}=0.476\left(\mathrm{MJ} \mathrm{m}^{-4} \mathrm{day}^{-1}\right), \mathrm{MAPE}=1.1 \%, \mathrm{RMSE}=0.68(\mathrm{MJ}$ $\left.\mathrm{m}^{-2} \mathrm{day}^{-1}\right), \mathrm{MAE}=0.06\left(\mathrm{MJ} \mathrm{m}^{-2} \mathrm{day}^{-1}\right)$.

$\mathrm{S} 3$ is the third best model with $\mathrm{R}=0.681, \mathrm{MSE}=1.423$ (MJ $\left.\mathrm{m}^{-4} \mathrm{day}^{-1}\right), \quad \mathrm{MAPE}=3.4 \%, \quad \mathrm{RMSE}=1.19 \quad\left(\mathrm{MJ} \mathrm{m}^{-2} \mathrm{day}^{-1}\right)$, $\mathrm{MAE}=-1.89\left(\mathrm{MJ} \mathrm{m}^{-2} \mathrm{day}^{-1}\right)$. Overall, the model H4performed best for all four studies with $\mathrm{R}$ value between 0.918 and 0.987 , RMSE value between 0.404 to 0.632 , MSE values between 0.163 and 0.404 and MAPE value between 1.1 and 5.1. The higher accuracy is obtained by using most relevant input attributes. The $\mathrm{H} 2$ has least performance, since model has developed with least attributes. H4 has highest accuracy, since it depends on most relevant attribute as Approximate SolarRadiationandTemperature.Therefore, theapproximate solar radiation and temperature data plays an important role for estimation of global solar radiation. Temperature input parameters gives best estimation for only pleasant climate such as Coimbatore, since the maximum temperature $35.9^{\circ} \mathrm{C}$ and minimum temperature is $19.8^{\circ} \mathrm{C}$.

In this section the performance of best evaluated parametricmodeliscomparedwithANN-STmodelbasedon their result. Thirteen models have developed using curve expert software for different location. And then it have analysed that ST based parametric model (H4) gives the best result during training the data. Similarly for ANN-ST model gives the best result with minimized error and improved performance. Comparison of measured and predicted data of ANNandEmpiricalmodelisshowninFig.6.InthisJan2018 data has predicted using both ST based model in ANN and Empirical. It shows that the ANN predicted data is high accuracy, while compared to the ST-empirical. Since the mathematical model derived is not well suited for the daily solar radiationprediction.

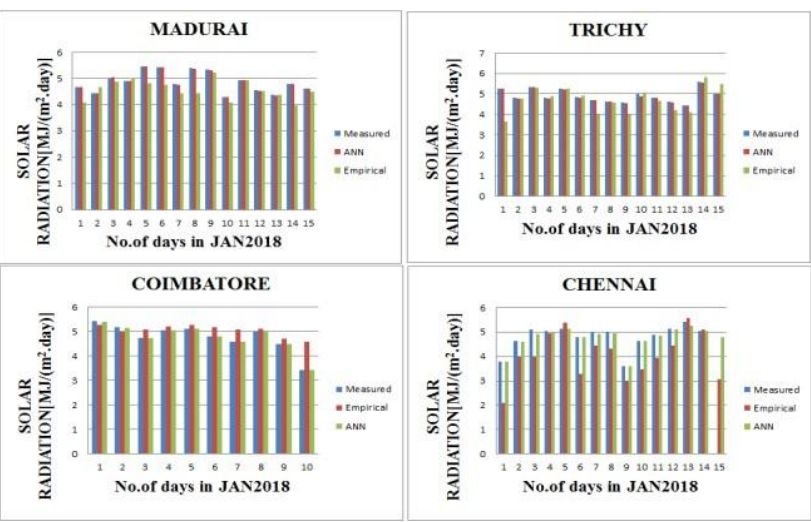

Fig .6. Evaluation of measured and predicted data of

ANN and Empirical model

Some of days predicted data is far different from measured data.AndforpredicteddataofANNisclosertothemeasured data.Itisachievedbytrainingalargenumberofdataanddata has learned by the network. The mean square error of ANN and empirical model is shown in Fig. 7. It is evaluated that error between the measured data and predicted data is minimized in ANN. So the prediction accuracy can be improved byANN.

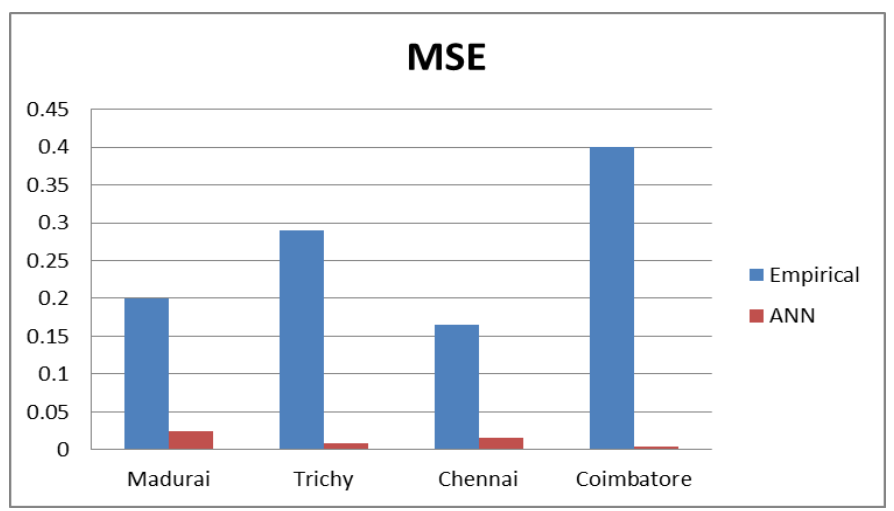

Fig .7. Mean square error comparison between ANN and Empirical

When compared to $\mathrm{ANN}$, the error calculated from the empirical is higher and the accuracy is minimized. Hencethe ANN - ST model can be used for predictive basedproblems. The performance indicator for both selected ANN-ST and Empirical-ST model is given in Table VI. The mean square error, mean absolute error, mean absolute percentage error, root mean square errorand regression coefficient are the statistical indicator which has calculated for four cities. Fromthe

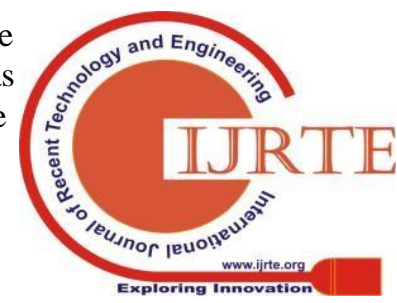




\section{Approximation of Empirical and ANN Based Solar Radiation Models for Four Smart Cities in Tamil Nadu with Most Prompting Input Parameters.}

tableitisanalyzedthatthehighestaccuracyisachievedusing ANN-ST model for four sites.

Table -VI: Performance indicators of the selected ANN-ST and Empirical-ST models for four sites.

\begin{tabular}{|l|l|l|l|l|l|}
\hline $\begin{array}{l}\text { Model/ } \\
\text { Location }\end{array}$ & MAE & $\begin{array}{l}\text { MA } \\
\text { PE }\end{array}$ & MSE & RMSE & R \\
\hline Empirical & $\begin{array}{l}\mathbf{( M J}_{\mathbf{m}^{-2} \mathbf{d a y}^{-}}^{\mathbf{1}^{-}} \\
\mathbf{( \% )}\end{array}$ & $\begin{array}{l}\mathbf{( M J}^{\mathbf{2}} \\
\mathbf{m}^{-\mathbf{4}} \mathbf{d a y}^{-\mathbf{1}} \mathbf{)}\end{array}$ & $\begin{array}{l}\mathbf{( \mathbf { M J }} \\
\mathbf{m}^{-\mathbf{2}} \mathbf{d a y}^{-\mathbf{1}} \mathbf{)}\end{array}$ & \\
\hline Madurai & 0.224 & 5.1 & 0.200 & 0.440 & 0.303 \\
\hline Trichy & 0.16 & 3.2 & 0.29 & 0.538 & 0.388 \\
\hline Chennai & 0.08 & 1.1 & 0.165 & 0.404 & 0.724 \\
\hline Coimbatore & -0.04 & 2.1 & 0.40 & 0.632 & 0.707 \\
\hline ANN & & & & & \\
\hline Madurai & 0.128 & 4.3 & 0.016 & 0.2076 & 0.990 \\
\hline Trichy & 0.149 & 3.0 & 0.022 & 0.173 & 0.982 \\
\hline Chennai & 0.086 & 1.8 & 0.007 & 0.134 & 0.996 \\
\hline Coimbatore & 0.055 & 1.0 & 0.003 & 0.110 & 0.938 \\
\hline
\end{tabular}

reaches in the month of January and April. And the lowest GSR value reaches in the month of October and December. And then for Coimbatore the highest GSR values reaches betweenJanuarytoAugustmonthandlowestvaluereachesin the month of September to December. The correlation between measured and estimated GSR is given in the scatter plots shown in Fig. 8. The regression is analyzed from best hybrid model H4 (ST) for four selected cities. It is noted that the correlation coefficient ranges from 0.9381 to0.9961.

Approximate

SolarRadiationandTemperatureissuitableforfourdifferent zones in Tamil Nadu. And unique model has developed for southernregion.

Initially for Coimbatore has the highest accuracy of $0.999,1$ since it has a mild climate and solar radiation is not varied rapidly. Next to it, Madurai is achieved the highest accuracy 2. of 0.998. And similarly for Trichy, the regression coefficient isabout0.992.ComparedthesefourcitiesChennaihaslowest

\section{VICONCLUSION}

In this work, the comparative studies have made between Empirical and ANN models for the prediction of GSR. Three sub-classes of model have developed namely temperature, sunshine and hybrid model. It is foundsunshine andtemperatureismostinfluencingparametersforestimation of daily GSR. And relative humidity is minimuminfluencing parameter. In both empirical and ANN, the combination of sunshineandtemperaturemodelgivesthebestresult.Further thisselectedbestmodelhastestedforfourcitiesin Tamil accuracy of 0.9883 . Similarly the error statistics has 7. calculated between the measured data and predicted data of empirical. The lowest accuracy has obtained for all sites. Since the daily the solar radiation data and temperature is 8 rapidly changes. Hence the Madurai and Trichy has a lowest accuracyof0.303and0.388. ChennaiandCoimbatorehasthe accuracy of 0.724 and 0.707 . Since these both has located in centralandwesternofTamilNadu.Butitsresultisnotcloser to 1, which denotes the highest accuracy. And compared to ANNST, the empirical-ST gives worst performance forfour

$$
\text { Hence } \mathrm{H} 4 \text { model with combination of }
$$

cities.HencetheANN-STmodelcanbeusedforpredictionof daily global solar radiation. This combination oftemperature andsunshinebasedANNmodelisbestforpredictionofdaily global solar radiation in southern states ofIndia.

Predicted and estimated daily average GSR of best hybrid modelH4forfourcitiesinTamilNaduisshowninFig.8.The average daily GSR computed for four smart cities of Tamil Nadu using H4model.

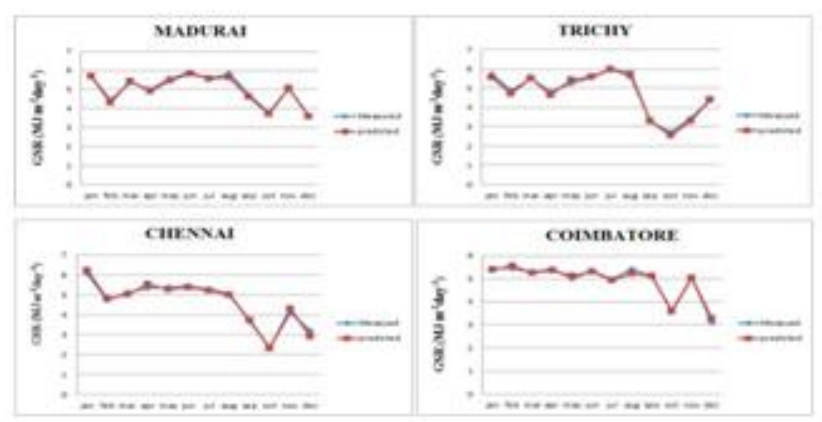

Fig .8. Comparison of Empirical (H4) with measured daily average GSR.

ForMaduraithemonthlymeandailyGSRreachesitshighest values between months of March to August. And GSR reaches its lowest value between months of September to February.AndthenforTrichyreachesitshighestvaluesinthe July month. And it reaches lowest value in the month of October.Similarly,fortheChennaithehighestGSRvalue Nadu and error statistics has calculated. The highest accuracy of ST based ANN model is 0.996 and ST based Empirical model is 0.707 . The accuracy of ANN - ST model is high, since the large number of data is learned during training process.Duetodeeplearningofthedata,itcouldachievethe required ANN target and over fitting is alsoreduced.

\section{REFERENCES}

Amrita Das, jin -ki park, Jong- hwa park, "Estimation of available global solar radiation using sunshine duration over south korea", Journal of Atmospheric and Solar - Terrestrial Physics,Vol.134, pp.22-29,2015.

V.H. Quej, J. Almorox, M. Ibrakhimov, L. Saito, "Estimating daily global solar radiation by day of the year in six cities located in the Yucatán Peninsula, Mexico", Journal of Cleaner Production,Vol.141, pp.75-82,2017.

3. C. Renno, F. Petito, A. Gatto, "ANN model for predicting the direct normal irradiance and the global radiation for a solar application to a residential building", Journal of Cleaner Production, Vol.135, pp.1298$1316,2016$.

4. Emanuel Federico alsina, Marco Bortotini, Mauro Gamberi, Alberto Regattieri, "Artificial Neural Network optimization for monthly average daily global solar radiation prediction", Journal of Energy Conversion and Management, Vol.120, pp.320-329,2016.

5. K.N. Shukla, Saroj Rangnekar, K. Sudhakar, "Comparative study of isotropic and anisotropic sky models to estimate solar radiation incident on tilted surface: A case study for Bhopal, India", Journal of Atmospheric and Solar-Terrestrial Physics, Vol.1, pp.96-103,2015.

6. Kadir Bakirci, "Prediction of global solar radiation and comparison with satellite data", Journal of Atmospheric and Solar-Terrestrial Physics, Vol.152-153, PP.41-49,2017.

D.I.Jeong,A.St-Hilaire,Y.Gratton,C.Belanger,C.Saad, "A guideline to selectan estimation model of daily global solar radiation between geostatic interpolation and stochastic simulation approaches", Renewable Energy, Vol.103, pp.70-80,2017.

A. Sharma, A. Kakkar, "Development of modified Pro-Energy algorithm for future solar irradiance estimation using level and trend factors in time series analysis", Journal of Renewable and Sustainable Energy, Vol.9, pp.1-16, 2017. 
9. H. Jiang, Y. Dong, "Global horizontal radiation forecast using forward regression on a quadratic kernel support vector machine: Case study of the Tibet Autonomous Region in China", Energy, Vol.133, pp.270 283,2017 .

10. F. Baser, H. Demirhan, “A fuzzy regression with support vector machine approach to the estimation of horizontal global solar radiation", Energy, Vol.23, pp.229-240,2017.

11. R. Meenal, A. immanuel selvakumar, "Assessment of SVM, Empirical and ANN based solar radiation prediction models with most influencing input parameters", Renewable energy,2017.

12. M. Vakili, S.R. Sabbagh-Yazdi, S. Khosrojerdi, K. Kalhor, "Evaluating the effect of particulate matter pollution on estimation of daily global solar radiation using artificial neural network modeling based on meteorological data", Journal of Cleaner Production, Vol.141, pp.12751285,2017.

13. B. Jamil, N. Akhtar, "Estimation of diffuse solar radiation in humidsubtropical climatic region of India: Comparison of diffuse fraction and diffusion coefficient models", Energy, Vol.131, pp.149-164,2017.

14. S.A. Kalogirou, S. Pashiardis, A. Pashiardi, "Statistical analysis andinter-comparisonoftheglobalsolarradiationattwositesin Cyprus", Renewable Energy, Vol.101, pp.1102-1123,2017.

15. Basharat Jamil, Abid T. Siddiqui, "Generalized models for estimation of diffuse solar radiation based on clearness index and sunshine duration in India: Applicability under different climatic zones", Journal of Atmospheric and Solar-Terrestrial Physics, Vol.157-158, pp.16-34,2017.

16. D.V. Siva Krishnan Rao K, M.Premalatha, C.Naveen, "Models for forecasting monthly mean daily global solar radiation from in-situ measurements: Application in tropical climate, India”, Journal of Urban Climate,2017.

17. Junliang Fan, Baiquan Chen, Lifengwu, Fucang Zhang, Xianghui Lu, Youzhenxiang, "Evaluation and development of temperature - based empirical models for estimating daily global solar radiation in humid regions", Journal of Energy, Vol.144,pp.903-914

18. Gasser E. Hassan, M.Elsayed Youssef, Zahraa E.Mohamed, Mohammed A.Ali, Ahmed A.Hanafy, " New temperature - based models for predicting global solar radiation”, Journal of Applied Energy,2016.

19. Amit kumar yadav, Hasmat Malik, S.S.Chandel, "Selection of most relevant input parameters using WEKA for Artificial Neural Network based solar radiation prediction models", Journal of Renewable and Sustainable Energy Reviews, Vol.31, pp.504-519,2014.

20. Salcedo-Sanz, Sancho \& Deo, Ravinesh C. \& Cornejo-Bueno, Laura\& Camacho-Gomez, Carlos \& Ghimire, Sujan, "An Efficient neuroevolutionary hybrid modeling mechanism for the stimation of daily global solar radiation in th sunshine state of Australia", Journal of Applied Energy,Vol.209@, pp.79-94, 2018

21. MauricioBrunoPradodaSilva,JoaoFranciscoEscobedo,Cicero Manoel dos Santos, Taiza Juliana Rossi, Silvia Helena Modenese Gorla da Silva, "Performance of the Angstrom-Prescott Model (A-P)and SVM and ANN Techniques to estimate the daily Global Solar Irradiationin Botucatu/SP/Brazil", Journal of Atmospheric

Vol.160, pp.11-23,2017 and Solar-Terrestrial Physics,

22. Sayed Saber Sharifi, Vahid Rezaverdinejad, Vahid Nouran "Estimation of Daily Global Solar Radiation using Wavele Regression, ANN, GEP and Empirical Models: A Comparative Study of Selected Temperature-Based Approaches", Journal of Atmospheric and Solar-Terrestrial Physics, Vol.149, pp.131-145,2016.

23. J.Vishnupriyan, P.s.Manoharan, V.Annapeachi, "Estimation of daily global solar radiation in tropical region in south India using linear regression and Artificial Neural Network", Journal of Electrical Engineering, 2018

24. V.Annapeachi, G.S.Gayathri, “ Assesment of day to day Global Solar Radiation in Tropical region of Tamil Nadu Using ANFIS Soft Computing Technique", International Journal of Engineering and Advanced Technology, 2019.

\section{AUTHORS PROFILE}

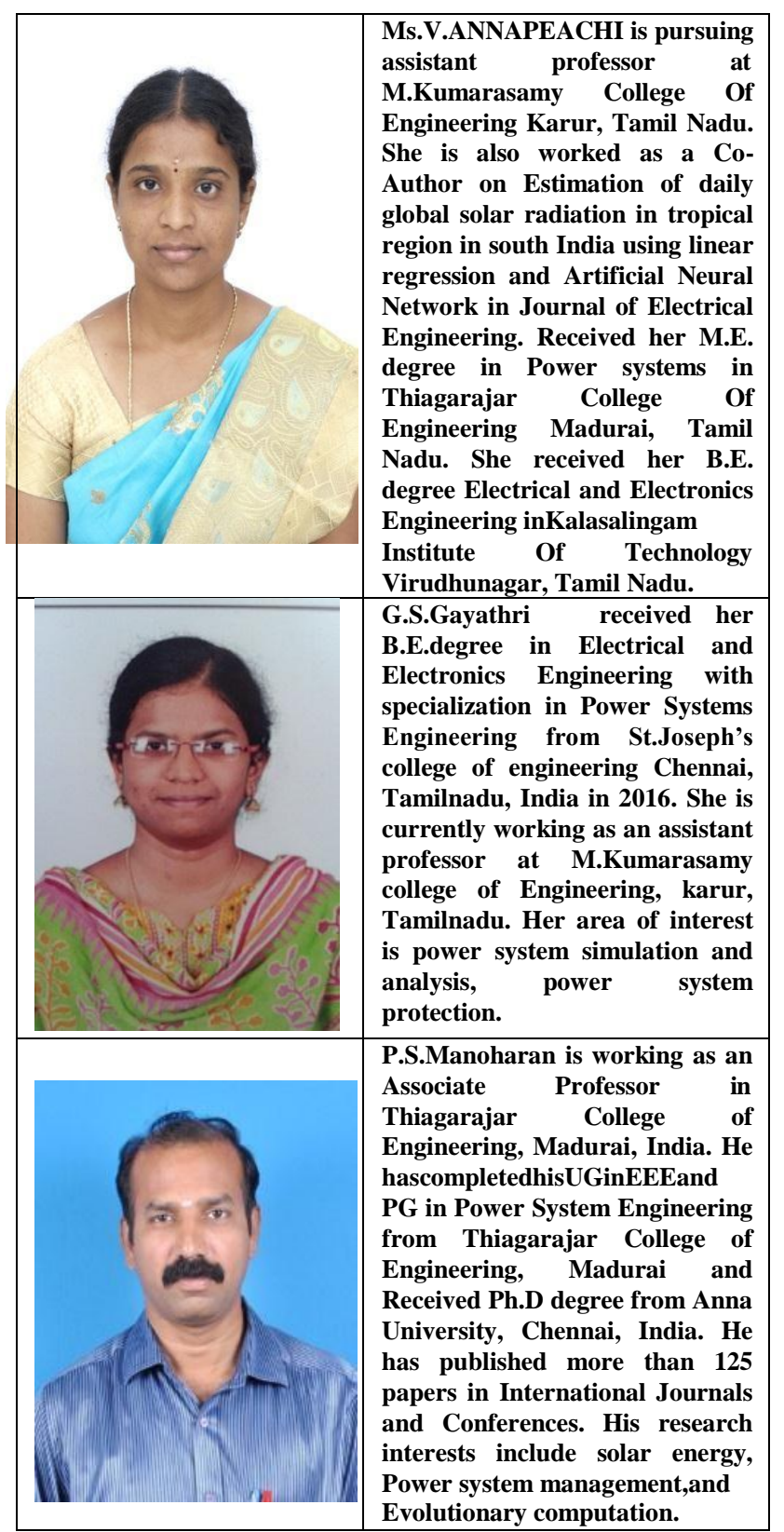

